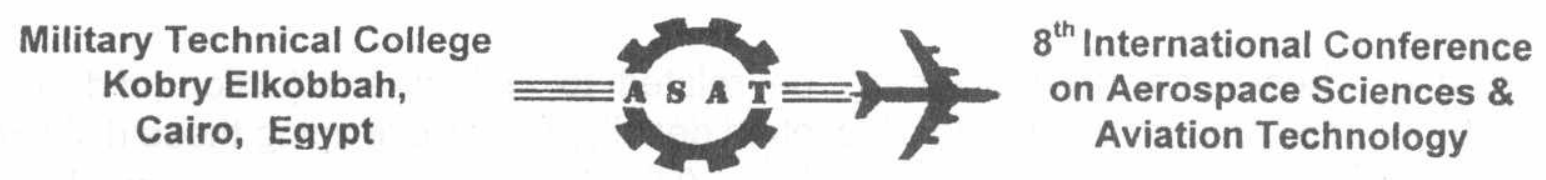

\title{
EFFECT OF THERMO-MECHANICHAL TREATMENTS ON THE MECHANICAL BEHAVIOUR OF AL-CU AND AL-Mg-Si ALLOYS
}

\author{
M.M.OSMAN*, A.M.EL-MAHALLAWY**, M.T.SALLAM***
}

\begin{abstract}
This investigation was carried out on two heat treatable aluminum alloys type-2014 (Al$\mathrm{Cu}$ ) and type-6082 (Al-Mg-Si) in order to evaluate their mechanical response against cold plastic strain either prior to or between the stages of aging. Standard flat specimens of the first alloy having a thickness of $3 \mathrm{~mm}$ were solution treated at $500^{\circ} \mathrm{C}$ for $1 \mathrm{hr}$ followed by quenching in water then immediately subjected to different percentages of cold plastic strain either prior to, orland between the stages of a double aging cycle. The first aging stage was carried out at $140^{\circ} \mathrm{C}$ for $55 \mathrm{hrs}$ while the second one at $170^{\circ} \mathrm{C}$ for $5 \mathrm{hrs}$. The specimens of the second alloy having the same thickness were also solution treated at a higher temperature of $535^{\circ} \mathrm{C}$ for $1 \mathrm{hr}$ and was also subjected to the same type of thermomechanical cycles, where aging of the first stage was done at $100^{\circ} \mathrm{C}$ for $15 \mathrm{hrs}$ and at $180^{\circ} \mathrm{C}$ for $5 \mathrm{hrs}$ in the second stage. The obtained results showed that, the application of $10 \%$ plastic strain prior to aging conjointly with $12 \%$ plastic working between the stages of double aging provide the utmost hardening effect to the Al-Cu alloy type-2014 by nearly doubling its strength. Moreover, the Al-alloy type-6082 showed a lower response to hardening compared with the Al-alloy type-2014. The application of $10 \%$ cold plastic strain prior to aging conjointly with $5 \%$ cold plastic strain between the stages of double aging increases the proof strength by $80 \%$ and decreases the ductility only by about $27 \%$.
\end{abstract}

\section{KEY WORDS}

Plastic strain, Solution treated, Thermo-mechanical treatment, Aging.

\section{INTRODUCTION}

Keen eyes are being cast over the techniques required to realize significant improvements in the properties of these alloys to replace heavy ferrous materials in different major applications. These improvements can be achieved by applying either a purely thermal or thermo-mechanical cycles [TMT]. It was shown by Starke [1] and Wyss [2] that TMT has a distinct effect in improving fracture toughness, fatigue, and stress corrosion cracking

* Assistant Lecturer, dep. of materials science and technology, MTC

** Dr. materials science and technology dpt., MTC

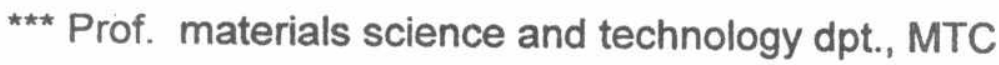


resistance. These improvements can be related to either a reduction of dislocation mobility or to an increase of the dislocation density. At artificial aging these dislocations provide heterogeneous nucleation sites for $\theta^{\prime}$ in the cold worked alloys, and lower the nucleation barrier for $\theta^{\prime}$ precipitation which increases the nucleation rate of $\theta^{\prime}$. On the other hand, to attain the advantage of low temperature aging, which secures a relatively fine dispersed nucleation centers for the second phase precipitates formed in this type of alloys, a low temperature aging cycle was applied before the implementation of the final aging cycle at the prescribed aging temperatures of these alloys.

The main objective of this research work is to investigate the influence of different thermomechanical treatments where cold plastic strain with different percentages is applied either prior to, and/or between the stages of double aging cycles, and determine the optimum parameters which provide the utmost hardning effect.

\section{EXPERIMENTAL WORK}

Standard flat specimens according to ASTM specifications having a thickness of $3 \mathrm{~mm}$ were cut from rolled sheets of the two alloys with its longitudinal axis in the rolling direction Fig. 1. The specimens of the first alloy type-2014 were solution treated at $500{ }^{\circ} \mathrm{C}$ while the specimeris of the second one type-6082 were solution treated at $535{ }^{\circ} \mathrm{C}$ for 1 hour to secure complete dissolution of the existing second phase particles which were formed during ariy previous age hardening treatment, then the specimens were quenched to room temperature to enhance the formation of a super saturated solid solution. Specimens of the two alloys were immediately artificially aged at a relatively low temperature $140^{\circ} \mathrm{C}$ for the alloy type-2014 and at $100^{\circ} \mathrm{C}$ for the alloy type-6082 for different times, cooled to room temperature, and then aged again at $170^{\circ} \mathrm{C}$ and $180^{\circ} \mathrm{C}$ respectively for 5 hours Fig.2-a. Another group of specimens were subjected to different percentages of cold plastic strain by tensile stretching prior to, and/or between the stages of aging cycle. The first aging stage was carried out for 55 hours in the case of Al-alloy type-2014, and the same was done for 15 hours in the case of the Al-alloy type-6082 Fig. 2. The determination of the tensile characteristics of the specimens after performing the TTMT was done using a $100 \mathrm{KN}$ Instron electro-hydraulic universal testing machine, model-8032 with autographic recording of the stress-strain curve to allow determination of the ultimate tensile strength and the ductility.

\section{RESULTS AND DISCUSSION}

The effect of aging time during an initial aging cycle at $140^{\circ} \mathrm{C}$ followed by a second aging cycle at $170^{\circ} \mathrm{C}$ for $5 \mathrm{hrs}$ on the tensile properties of the Al-alloy type-2014 is illustrated in Fig.3. It can be stated that the effect of this double stage aging process is not remarkable on the ultimate tensile strength while after a prolonged aging at the initial aging cycle over $60 \mathrm{hrs}$. an increase of about $25 \%$ in proof stress can be obtained. 


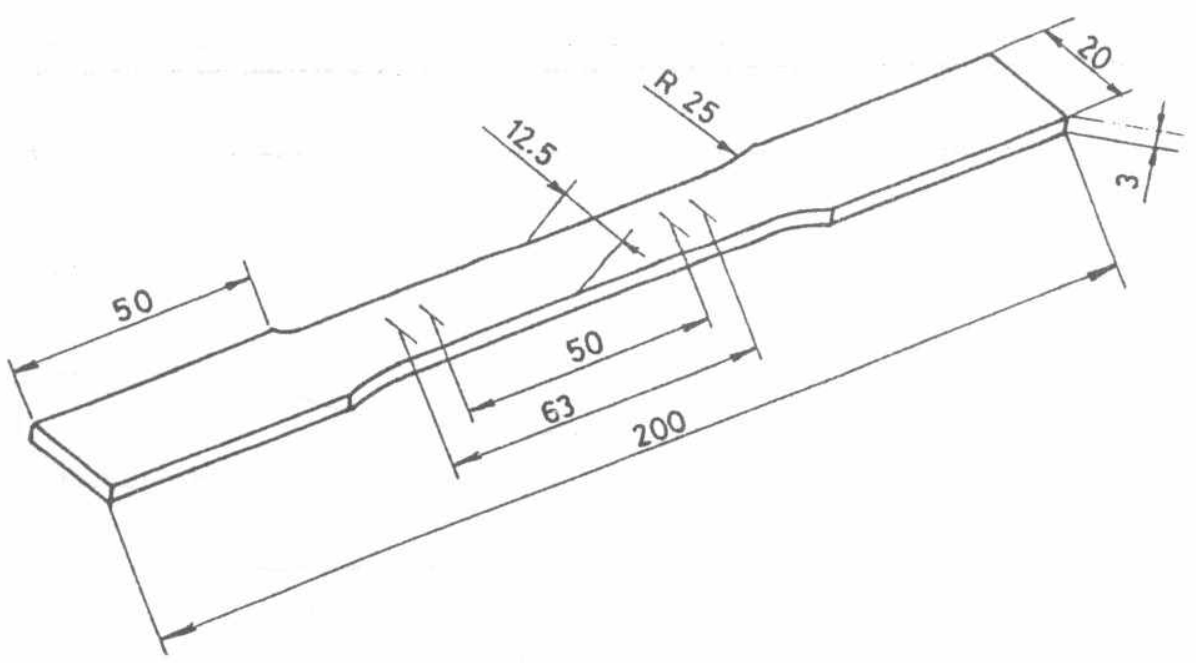

Fig. 1 . Standard flat tensile specimen according to ASTM.

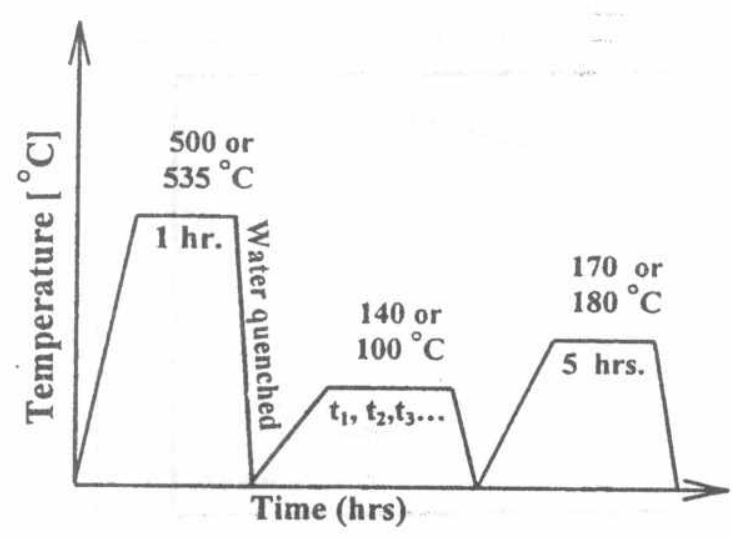

(a) Double stage aging.

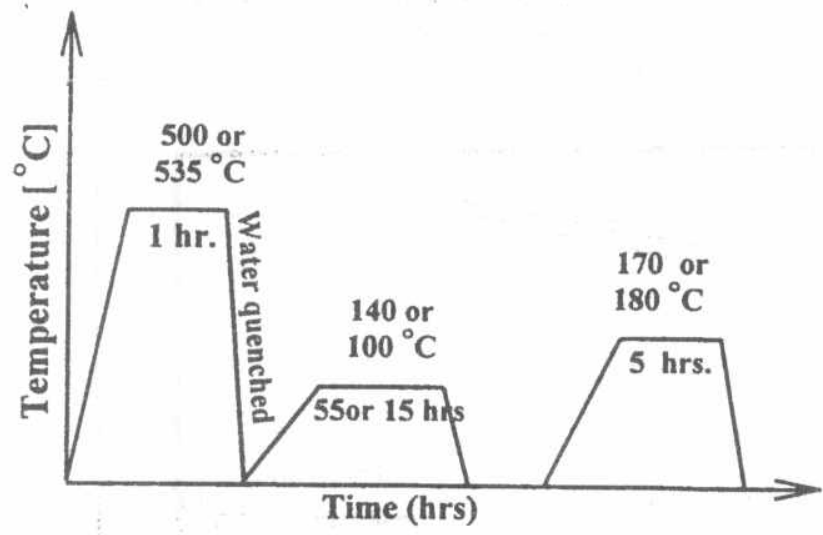

(C) P.D between the stages of double aging.

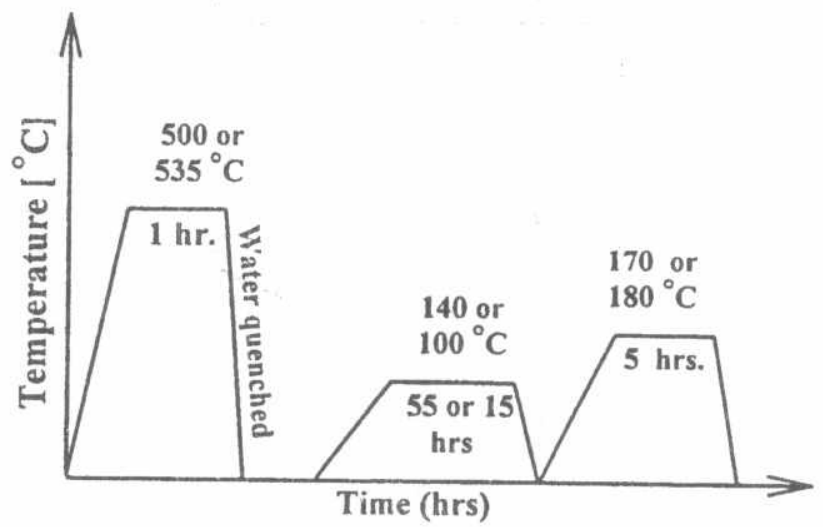

(b) P.D prior to aging.

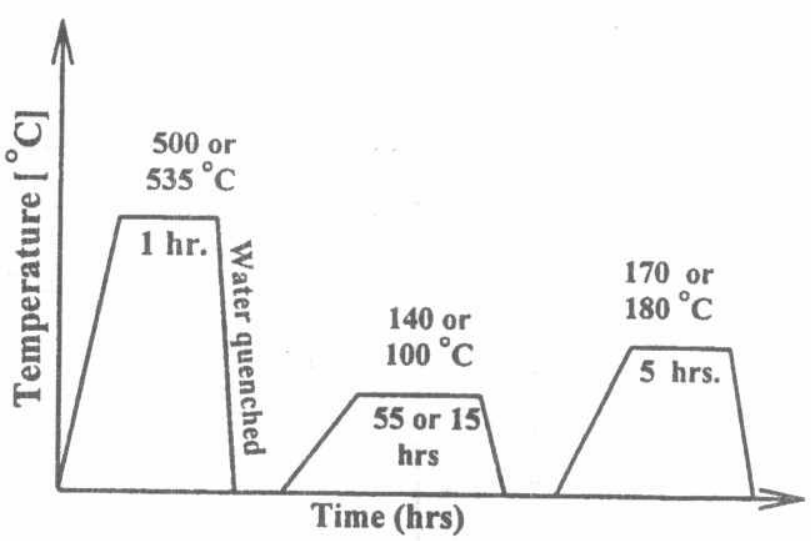

(d) P.D prior to and between the stages of double aging.

Fig. 2. Thermo-mechanical aging cycles. 


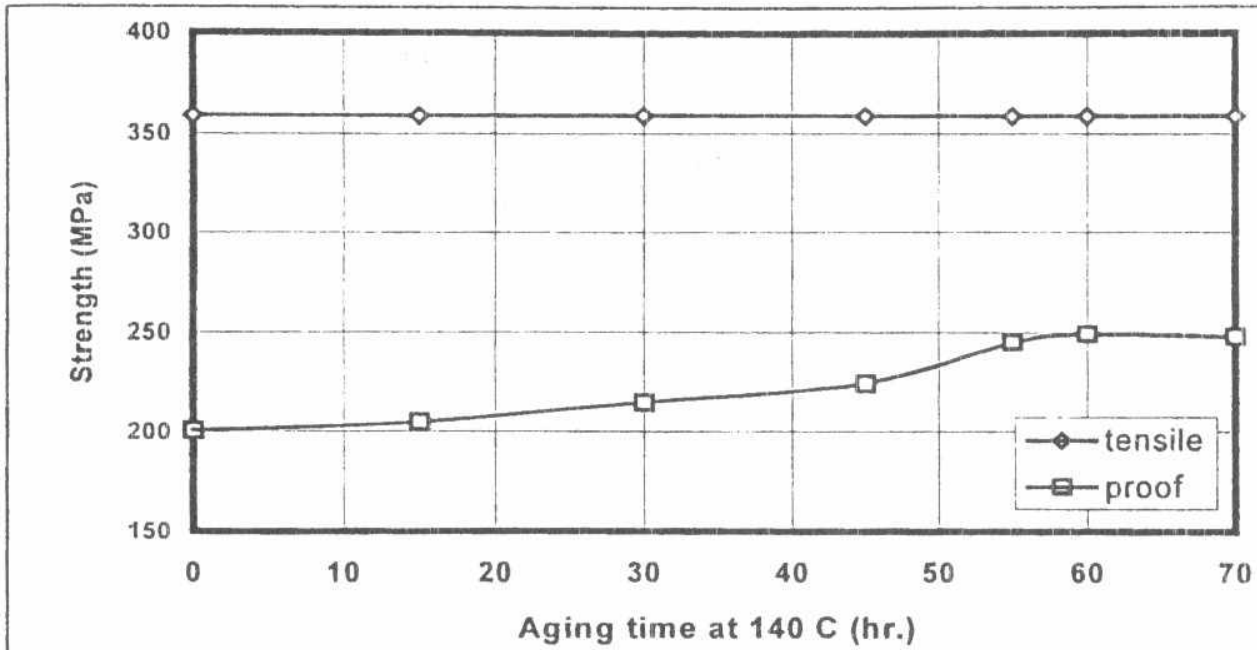

Fig.3 Effect of aging time during an initial aging cycle at $140^{\circ} \mathrm{C}$ followed by a second aging cycle at $170^{\circ} \mathrm{C}$ for $5 \mathrm{hrs}$ on the strength of $\mathrm{Al}-\mathrm{Cu}$ allov tvne-2014.

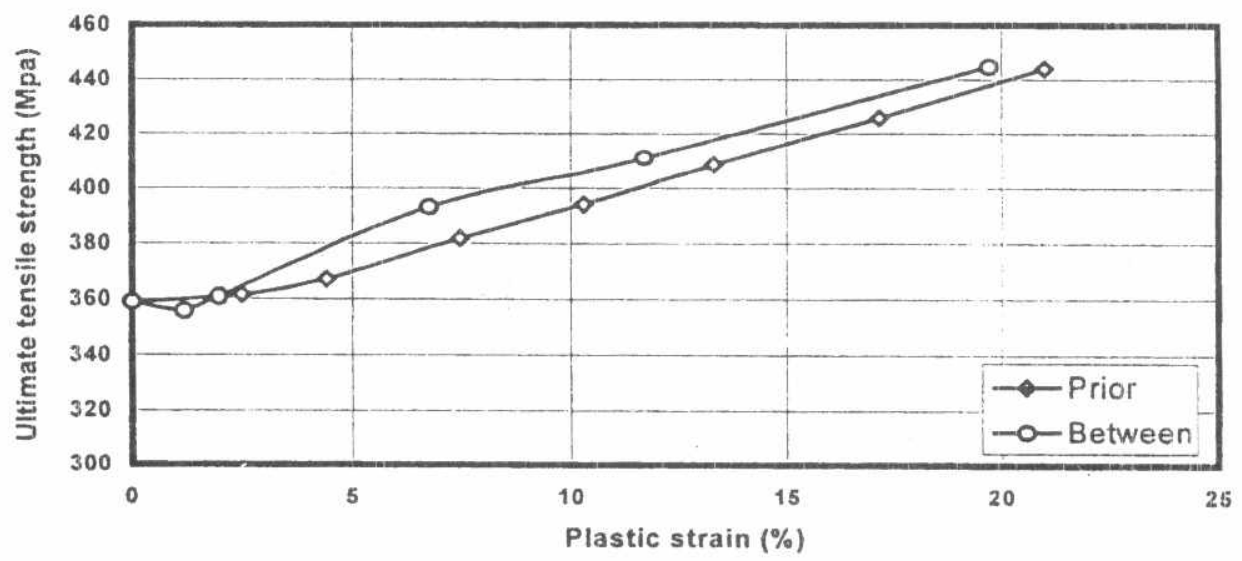

Fig.4 Effect of percentages plastic strain prior to, or between the two stages of double aging on the tensile strength of Al- alloy type-2014.

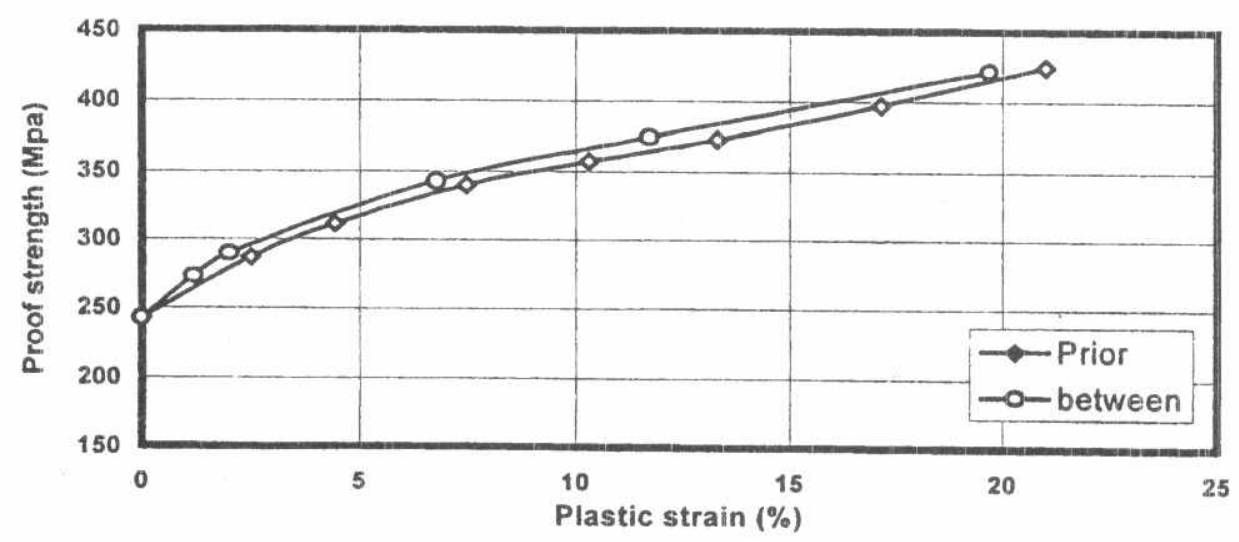

Fig. 5 Effect of percentages plastic strain prior to, or between the two stages of double aging on the proof stress of the Al-Cu alloy type-2014. 
In the goal of seeking for the utmost improvements of mechanical tensile properties of this alloy, the plastic working was also introduced to this improved purely thermal cycle with double aging stages. The designed thermo-mechanical cycle with different percentages of plastic strain prior to the stages of double aging is shown in Fig.2-b. , while Fig.2-c. shows another cycle with plastic strain between the two stages of aging.

Fig.4. and 5. illustrate the effect of the percentage plastic strain prior to, or between the two stages of double aging on the ultimate and the proof stress of Al-Cu alloy type2014. It can be noted that a nearly linear building up of strength takes place as the percentage of plastic working increases without any observed saturation up to $20 \%$ plastic strain. Moreover the resulting degree of hardening is very similar in both types of thermo-mechanical treatments inspite of the difference in the sequence of plastic working with respect to the aging. An increase of about $16 \%$ in ultimate strength and of about $60 \%$ in proof stress can be attained by the application of $15 \%$ plastic strain. On the other hand, the application of the same percentage of cold plastic working reduces the ductility to one half of its value when the double aging treatment is carried out without any plastic strain as shown in Fig.6.

Fig.2-d. shows a thermo-mechanical treatment with plastic working prior to, and between the two stages of double aging. Fig.7. and 8. illustrate the effect of cold plastic working between the double stages of artificial aging on the tensile and proof strength of $\mathrm{Al}-\mathrm{Cu}$ alloy type-2014 respectively for different percentages of plastic stretching namely $0 \%, 5 \%, 10 \%$ prior to the double aging treatment. We can observe in the first stage a softening effect up to about $2 \%$ plastic strain, this softening effect becomes more pronounced with increasing the percentage deformation prior to aging. This first stage is followed by a second stage where the strength increases in a progressive manner for all the percentages of plastic working prior to aging and exceeds its value when $0 \%$ plastic strain between the two stages of the double aging is applied. This behaviour can be explained by the simultaneous interference of two distinct effects, the first leading to softening of the alloy while the other leading to its hardening. In fact, it was shown that plastic working promotes diffusion and premature evolution, coarsening and non coherency of the second phase particles which can lead to a decrease of the alloy strength. In the same time the plastic working enhances the dislocation multiplication, intersection and interaction with solute atoms and the precipitates, that can lead to an increase of alloy strength. In the first stage the hardening effect is very limited and the softening effect dominates and manifests on the diagram then it is quickly counter balanced by the hardening effect which prevails in the second stage. This phenomenon can also be visualized in Fig.9. where the obtained ductility increases slightly in the first stage, then it is quickly decreased with increasing percentage of plastic strain between the stages of double aging.

Fig.10. shows the effect of aging time of the low temperature stage of the applied double aging cycles on the strength of this alloy. Ultimate and proof strength increase 


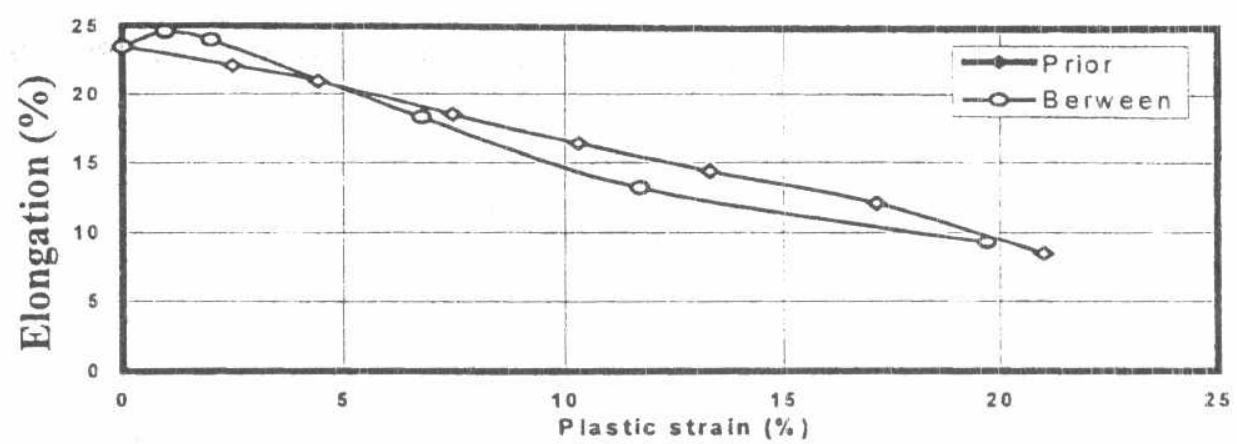

Fig.6. Effect of percentages plastic strain prior to, or between the two stages of double aging on the ductility of Al-Cu allov type-2014.

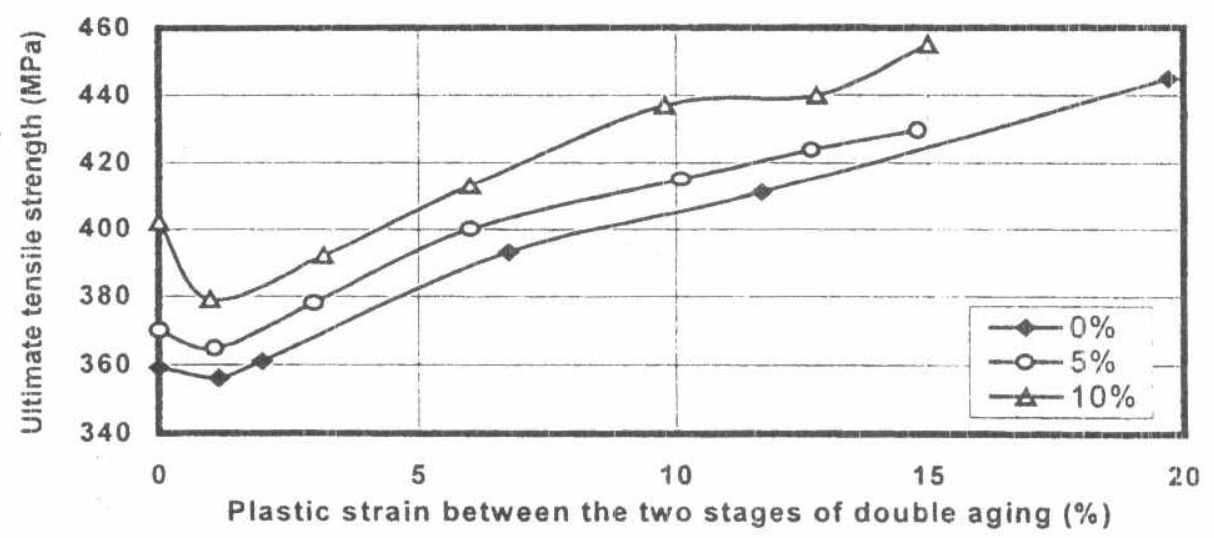

Fig.7. Effect of plastic strain between the two stages of double aging with different percentages of plastic strain prior to aging on the ultimate tensile strength of $\mathrm{Al}-\mathrm{Cu}$ alloy type-2014.

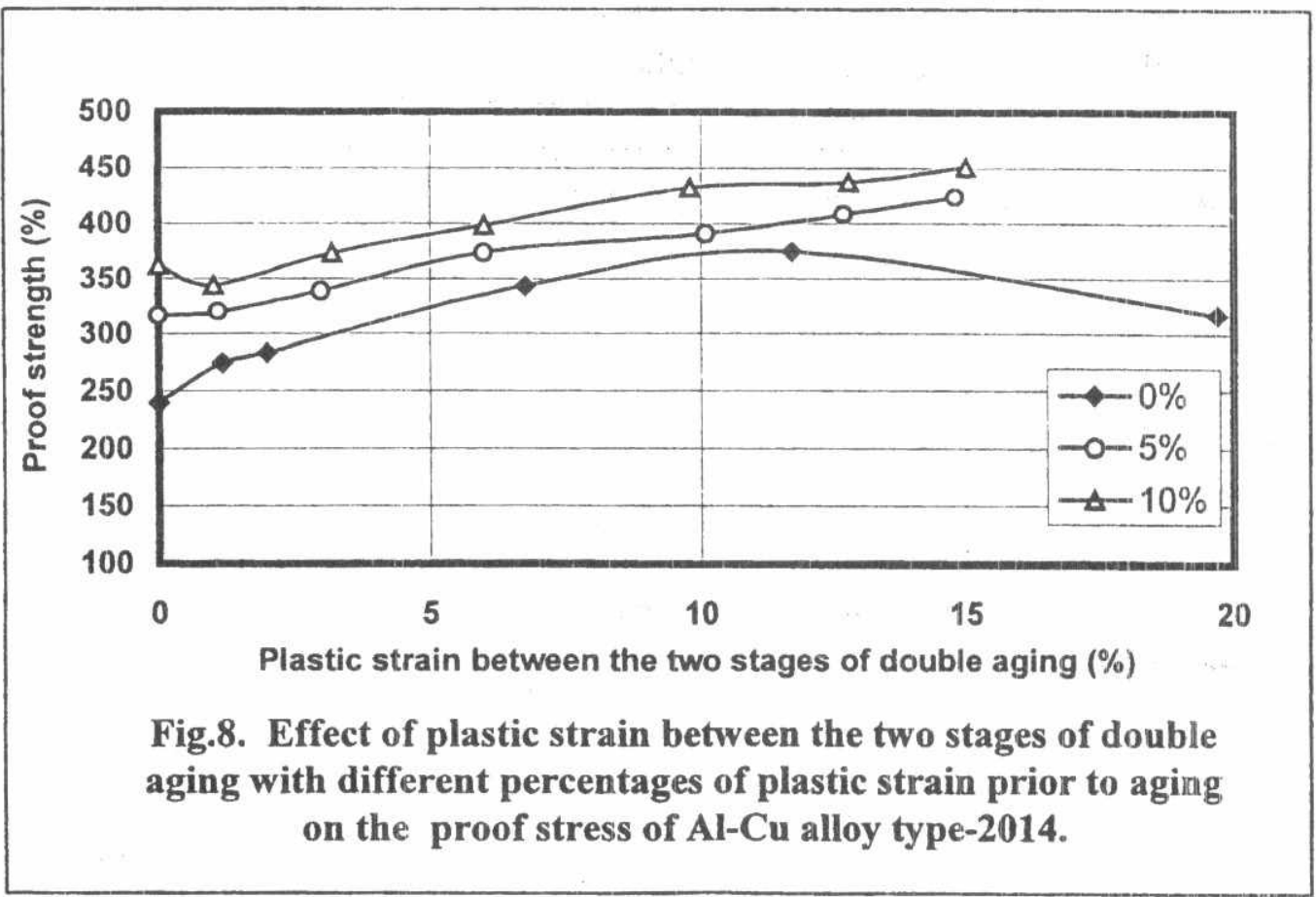




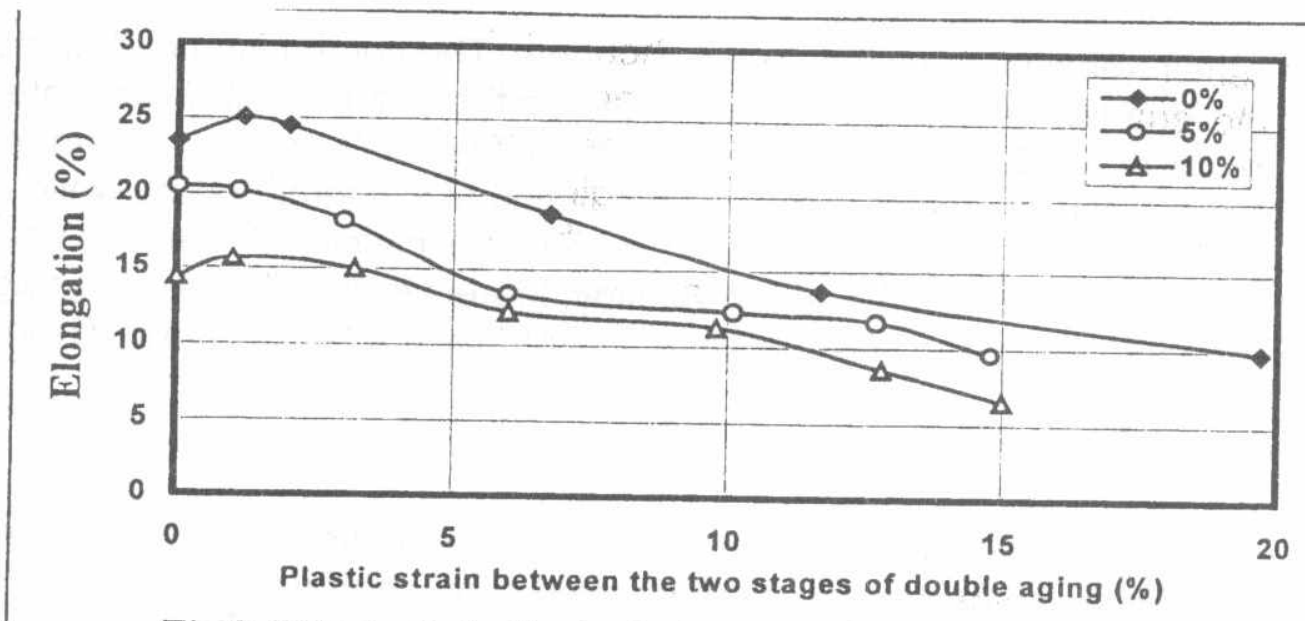

Fig.9. Effect of plastic strain between the two stages of double aging with different percentages of plastic strain prior to aging on the ductility of Al-Cu alloy type-2014.
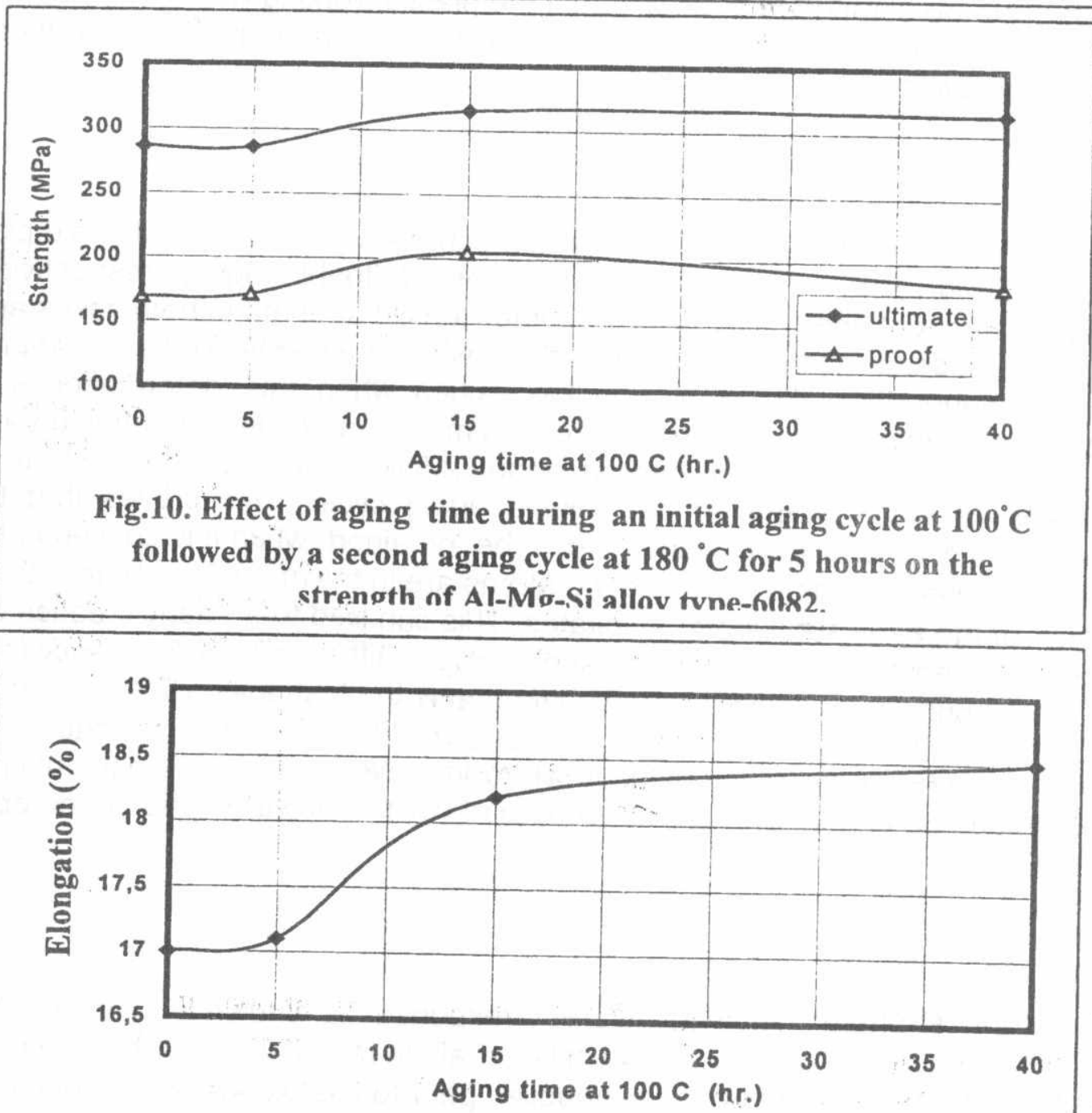

Fig.11. Effect of aging time during an initial aging cycle at $100^{\circ} \mathrm{C}$ followed by a second aging cycle at $180^{\circ} \mathrm{C}$ for 5 hours on the ductility of Al-Mg-Si alloy type-6082. 
and attain their maximum values after 15 hours. The comparison of the effect of this type of double aging cycle on both the Al-Cu and the Al-Mg-Si alloys indicates that the resulting value of hardening is very near, nevertheless the maximum hardening in the former alloy is obtained after about $60 \mathrm{hrs}$ aging at low temperature while it appears after about $15 \mathrm{hrs}$. in the later alloy. This can be explained by the high coefficient of diffusion of solute atoms in the Al-Mg-Si alloy. Moreover this double stage aging cycle has a littie effect in improving the ductility of the Al-Mg-Si alloy as shown in Fig.11.

It was known that [3], the superimposed effect of mechanical working on the thermal effect of classical aging with single cycle showed a net improvements in the mechanical properties of these two alloys, and in this work the composite thermal effect of double aging cycles proved that it has beneficial effect on the alloy mechanical properties. To combine the favourable mechanical working effect together with the enhancement provided by the composite thermal effect the plastic working was carried out either prior to or between the two aging cycles, or it is carried mutually prior and then between these aging cycles.

Figs.2-b. and 2-c. illustrate the thermo-mechanical treatments with cold plastic strain either prior to or between the two stages of double aging, respectively. Fig. 12 illustrates the obtained results of ultimate tensile strength in both cases and showed that the values of the maximum hardening when the plastic working is applied prior to aging is higher than the corresponding values when this deformation is carried out between the aging cycles. Furthermore, this maximum value is manifested at about $6 \%$ plastic strain while it is provided at about $2.5 \%$ when the plastic strain is applied between the two stages of the double aging cycle. This proves that the utmost beneficial effect of plastic working can be obtained when it is applied in the state of super-saturation where all the solute atoms are in the natrix and before the formation of any of the early stages of precipitates. This can lead to an early creation of plenty of nucleation centers and enhanced short range diffusion by the vacancy formation. In fact, the application of cold plastic strain after the first aging cycle does not alter to a great extent the nucleation pattern provided oy this first low temperature cycle but it may affect the further formed nuclii [4]. Ar improvement of $22 \%$ in the ultimate tensile strength can be obtained by the applicaticı of $6 \%$ plastic strain prior to the double stage aging cycle.

The proof strength showed different response as shown in Fig.13., it increases continuously up to about $20 \%$ plastic strain in both cases and its values are slightly higher when the plastic working is applied prior to the two stages of double aging. The yield strength of the specimens have been exposed to the double stage aging cycle can be raised by about $15 \%$ by the application of $16 \%$ cold plastic working prior to the double stage aging cycle. 


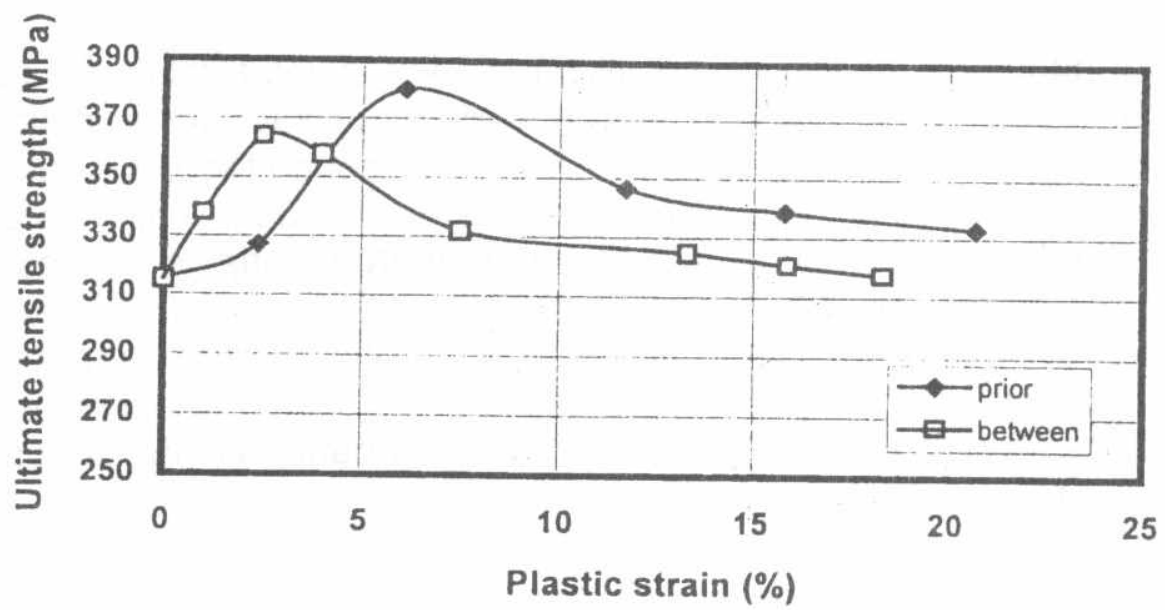

Fig.12. Effect of plastic strain prior to, or between the stages of double aging on the ultimate strength of Al-Mg-Si alloy type-6082.

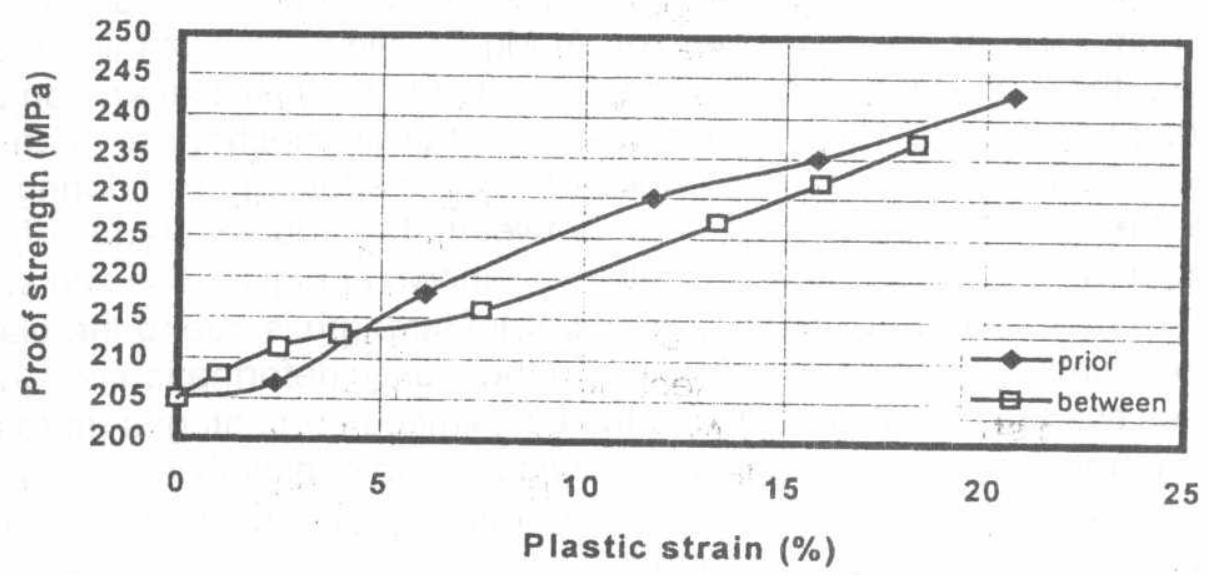

Fig.13. Effect of plastic strain prior to, or between the stages of double aging on the proof strength of Al-Mg-Si alloy type-6082.

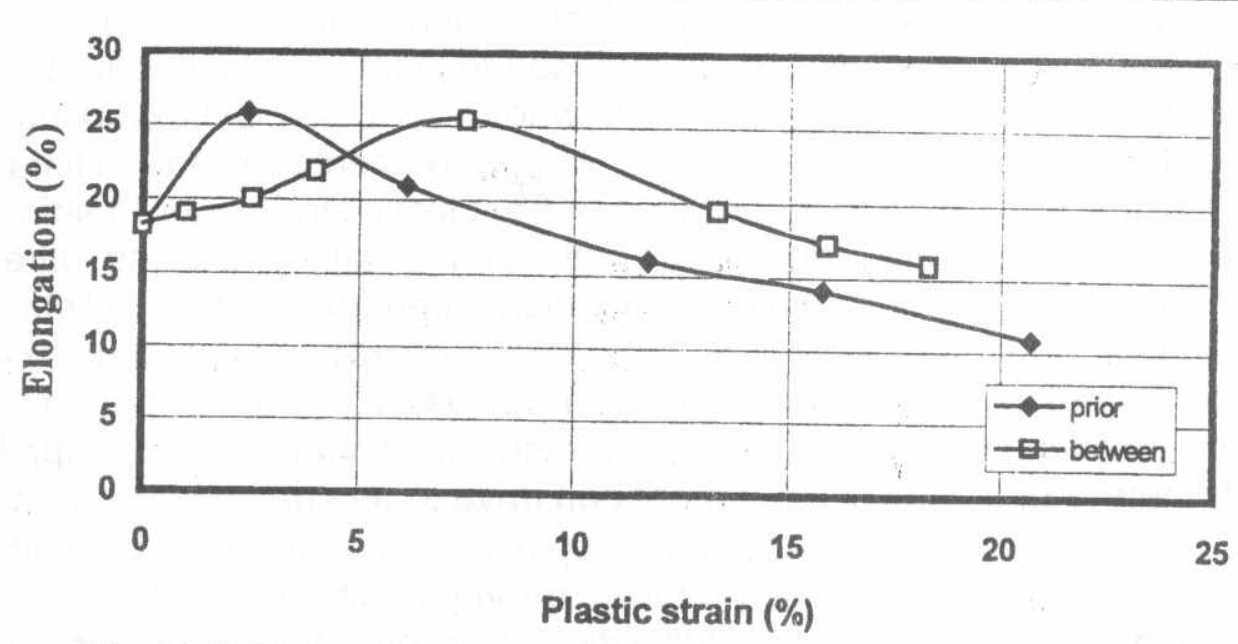

Fig.14. Effect of plastic strain prior to, or between the two stages of double aging on the ductility of Al-Mg-Si alloy type-6082. 
On the other hand, the ductility of this alloy Fig.14. showed a relatively important rise of its values as a first stage at low percentages of plastic working either prior to, or between the double stage aging cycle. In the second stage, the ductility is reduced gradually with increasing the amount of plastic working. The explanation of this behaviour may lie in the interaction of the numerous effects of plastic deformation during the thermo-mechanical cycle [5]. Plastic deformation may lead to a partial or complete non-coherency of some of the second phase particles formed in this type of alloys which offers the alloy additional softening. The other effects which have their impact in improving the strength become more pronounced in the second stage where the percentage plastic strain is important.

The previous evaluation of the combined effects of plastic strain of either prior to or between the two stages of double aging separately and the thermal treatment provided by the low and high temperature aging cycles proved to be very positive in improving the concerned mechanical properties of Al-Mg-Si alloy. The obtained encouraging results made the application of the these two types of plastic strain conjointly a logic and important further step. Fig.2-d. illustrates this thermo-mechanical treatment applied to this type of alloys. The mutual effect of plastic strain applied during this thermomechanical treatment both prior to and between the double stages of aging on the proof strength of the used Al-Mg-Si alloy is shown in Fig.15. We can state that, the major effect of hardening and the increase in proof strength is due to the plastic working prior to aging relative to the same effect when the plastic deformation is carried out only between the two stages of aging. Nevertheless, limited percentages up to about $4 \%$ of plastic strain between the double stage aging cycle conjointly applied with $5 \%$ up to $10 \%$ plastic working prior to aging can almost provide the maximum output hardening effect of such thermo-mechanical treatment.

Fig.16.illustrates the effect of both types of plastic strain on the ultimate tensile strength of Al-Mg-Si alloy. When this alloy is not exposed to plastic working prior to aging, the ultimate tensile strength shows a maxima when $3 \%$ cold plastic working is applied between the two stages of aging, for the higher percentages the ultimate tensile strength is sharply reduced. The application of $5 \%$ plastic strain prior to aging provides the highest possible ultimate tensile strength ever obtained by any other type of treatments carried out on this alloy. This high strength value is slightly reduced when cold plastic working between the aging cycles conjointly applied up to about $4 \%$, where the strength of this alloy starts to deteriorate sharply for higher percentages. This effect can be explained by the fact that, the excessive combined strain applied during this type of thermo-mechanical treatment can drive to a serious heavy damage of the material by the cumulative effect of piled up dislocations arrested by obstacles, this effect can originate different micro-cracks during plastic interval from yielding to ultimate leading to premature fracture formation. This interpretation is confirmed by the drop of the ultimate strength observed in the case when $10 \%$ plastic working prior to aging is applied, and the reduction of the ductility of this alloy with plastic strain as shown in Fig.17. 


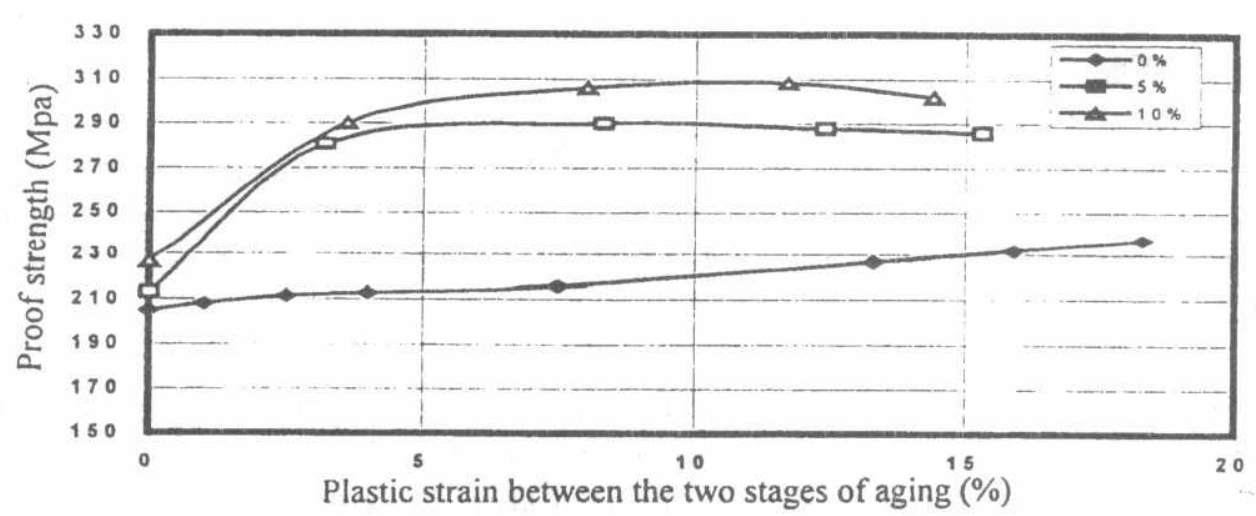

Fig.15. Effect of plasti strain between the two stages of double aging with different percentages of plastic strain prior to aging on the proof strength of $\mathrm{Al}-\mathrm{Mg}-\mathrm{Si}$ allov tvpe-6082.
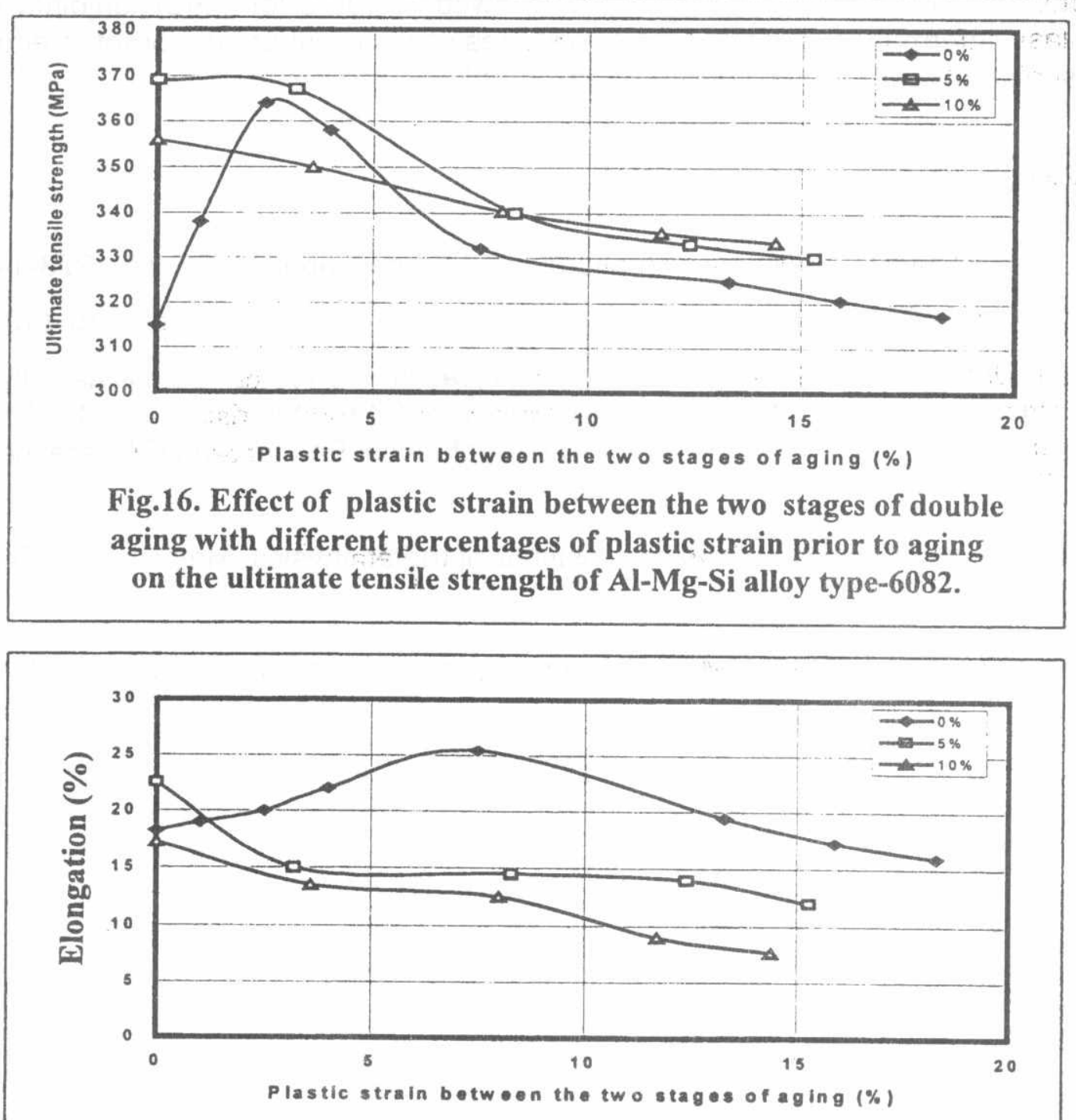

Fig.17. Effect of plastic strain between the two stages of double aging with different percentages of plastic strain prior to aging on the ductility of Al-Mg-Si alloy type-6082. 


\section{CONCLUSIONS}

1-For the Al-alloy type- 6082 the application of about $14 \%$ cold plastic strain prior to double aging ( $55 \mathrm{hrs}$ at $140^{\circ} \mathrm{C}$ followed by $5 \mathrm{hrs}$ at $170^{\circ} \mathrm{C}$ ), offered $15 \%$ improvement in ultimate tensile strength and about $50 \%$ in proof strength. Nevertheless, the obtained ductility was nearly reduced to $50 \%$.

2-For the same alloy the application of $10 \%$ plastic strain prior to aging conjointly with $12 \%$ plastic working between the two stages of aging provided the utmost possible hardening effect on this alloy by nearly doubling its strength.

3- For the Al-Mg-Si alloy type-6082 the utmost improvement in strength with a reasonable high ductility can be obtained by exposing this alloy to $10 \%$ cold plastic strain prior to double stage aging $\left(100^{\circ} \mathrm{C}\right.$ for $15 \mathrm{hrs}$ followed by $180^{\circ} \mathrm{C}$ for $5 \mathrm{hrs}$ ) conjointly with $5 \%$ cold plastic deformation between the two stages of aging, where the proof strength increases by about $80 \%$ and the ductility decreases only by about $27 \%$.

\section{REFERENCES}

[1] K. Asano and A. Fujiwara, Metallurgical TOransactions Vol.4, pp.1973-1499, (1972).

[2] R. Graff, Public Scientifique et Techniques du Ministere de l'Air pp.315, (1956).

[3] M. Osman, A.M.EL-Mahallawy, and M.T.sallam "Effect Of Cold Plastic Working Prior To, Or During Aging On The Mechanical Characteristics Of Al-Cu And Al-Mg-Si Alloys." $8^{\text {th }}$ Int. Applied Mechanics And Mechanical Engineering Conference, CAIROEGYPT, 1998

[4] N. N. Buynov and L. I. Osokina, Institute of metal physics, Metals, Vol. 24, No.4, pp. 59-65, (1967).

[5] E. Ryans and J. Ktein, Materials science and engineering, Vol.52, pp. 271-275, (1981). 